\title{
A review on modeling, identification and servo control of robotic excavator
}

\author{
Yan Jun, Li Bo, Zeng Yonghua, and Qian Haibo \\ Engineering Institute of Corps of Engineer, PLA University of Science and Technology, Nanjing, 210007, CHINA \\ ${ }^{*}$ Corresponding Author: e-mail: libomusic@163.com, Tel. +86-25-80822019
}

\begin{abstract}
Robotic excavator is a hydraulic actuated 4 DOF manipulator mounted on a mobile chassis which implements automatic excavations. This article reviews modeling, identification, and low level control of the robotic excavator. First, modeling of the nonlinear hydraulic dynamics, coupling manipulator dynamics, and soil-tool interaction dynamics are reviewed. Then, methods for identification of the established models are discussed. Finally, robust position control and compliance control of the robotic excavator are investigated.
\end{abstract}

Keywords: robotic excavator; modeling and identification; robust position control; compliance control.

\section{Introduction}

Hydraulic excavators are versatile machines which are widely used in construction, forestry, and mining industries. These machines are operated by humans for tasks: lifting, carrying, digging and ground leveling in a series of repetitive operations. The automation of these excavation tasks provides benefits such as improving productivity by enabling machines to drive at a higher average speed, reducing dependence on operator skills by computer coordination control, enhancing safety by separating the human from the machine when working in hazardous environments (Płonecki et al., 1998; Ha et al., 2002). Also, a robotic excavator is expected to work in lunar and planetary construction sites (Singh, 1997).

For automatic control, reconfiguration of excavator's control system is necessary. A normal excavator is a typical hydraulically actuated heavy-duty machine manipulated by humane to complete excavation tasks, its working mechanism is a 4 DOF hydraulic manipulator mounted on a mobile chassis. Generally, an electro-hydraulic control system is installed on a robotic excavator as well as instruments such as: position transducers, inclinometers, pressure transducers, and vision sensors (Bradley et al., 1998; Yan et al., 2011). The retrofitted excavator is monitored and controlled by computers instead of humans, and the robotic technology is applied to it (Ha, 2004).

This article reviews the modeling, identification and servo control issues of robotic excavators. It first examines the hydraulic control system model, bucket-soil interaction dynamic model, kinematic and dynamic model of the mechanism. Then, it summarizes the identification methods for the unknown parameters of the established models. Finally, the existent servo control methods are reviewed and discussed.

\section{System modeling}

Dynamic models describing the behavior of robotic excavator are needed for system analysis and controller design. This section focuses on modeling of the actuator dynamics, soil-tool interaction dynamics, manipulator kinematics and dynamics.

\section{1 actuator models}

Hydraulic actuators have a number of characteristics which complicate the development of precise model and high-performance controller. The oil viscosity, oil flow through the spool valves, and variable loading, cause the hydraulic actuation system to suffer 
from highly nonlinearities, load sensitivity, and parameter uncertainty (Ha et al., 2000). Furthermore, it may be subjected to nonsmooth and discontinuous nonlinearities due to input saturation, directional change of asymmetric cylinder, friction and valve overlap (Yao et al., 2000). A simplified linear model was developed for a load independent flow distribution system on a robotic excavator (He et al., 2008), but it is not applicable to others.

The system under consideration is a valve controlled single-rod hydraulic cylinder. The schematic of the system is depicted in Fig.1. Where $F_{f}$ represents the nonlinear friction force; $F_{l}$ is external force. Thus, a nonlinear state model is obtained based on the relationship between the valve displacement $x_{v}$ and the fluid flow to the head side $Q_{1}$ and from the rod side $Q_{2}$, the continuity of flow in the cylinder, and the force balance equation for the piston (Shahram, 1997).

By defining a state vector as: $\left[x_{1}, x_{2}, x_{3}, x_{4}\right]^{T}=\left[y, \dot{y}, P_{1}, P_{2}\right]^{T}$, one arrives the following nonlinear state space equations for hydraulic actuator(Quang, 2000):

$$
\begin{aligned}
& \dot{x}_{1}=x_{2} \\
& \dot{x}_{2}=\frac{A_{1} x_{3}}{M}-\frac{A_{2} x_{4}}{M}-\frac{B_{p} x_{2}}{M}-\frac{K x_{1}}{M}-\frac{F_{f}+F_{l}}{M} \\
& \dot{x}_{3}=-\frac{\beta_{e} A_{1} x_{2}}{V_{1}}-\frac{\beta_{e}\left(C_{i}+C_{e}\right) x_{3}}{V_{1}}+\frac{\beta_{e} C_{i} x_{4}}{V_{1}}+\frac{\beta_{e} g_{1}(x)}{V_{1}} x_{v} \\
& \dot{x}_{4}=\frac{\beta_{e} A_{2} x_{2}}{V_{2}}+\frac{\beta_{e} C_{i} x_{3}}{V_{2}}-\frac{\beta_{e}\left(C_{i}+C_{e}\right) x_{4}}{V_{2}}-\frac{\beta_{e} g_{2}(x)}{V_{2}} x_{v}
\end{aligned}
$$

Where, $g_{1}(x)=\operatorname{sgn}\left(\left(1+\operatorname{sgn}\left(x_{5}\right)\right) \frac{P_{s}}{2}-\operatorname{sgn}\left(x_{5}\right) x_{3}\right) C_{d} w \sqrt{\frac{2}{\rho}\left(\left(1+\operatorname{sgn}\left(x_{5}\right)\right) \frac{P_{s}}{2}-\operatorname{sgn}\left(x_{5}\right) x_{3}\right)}$,

$g_{2}(x)=\operatorname{sgn}\left(\left(1-\operatorname{sgn}\left(x_{v}\right)\right) \frac{P_{s}}{2}+\operatorname{sgn}\left(x_{v}\right) x_{4}\right) \not C_{d} w \sqrt{\frac{2}{\rho}\left(\left(1-\operatorname{sgn}\left(x_{v}\right)\right) \frac{P_{s}}{2}+\operatorname{sgn}\left(x_{v}\right) x_{4}\right)}$.

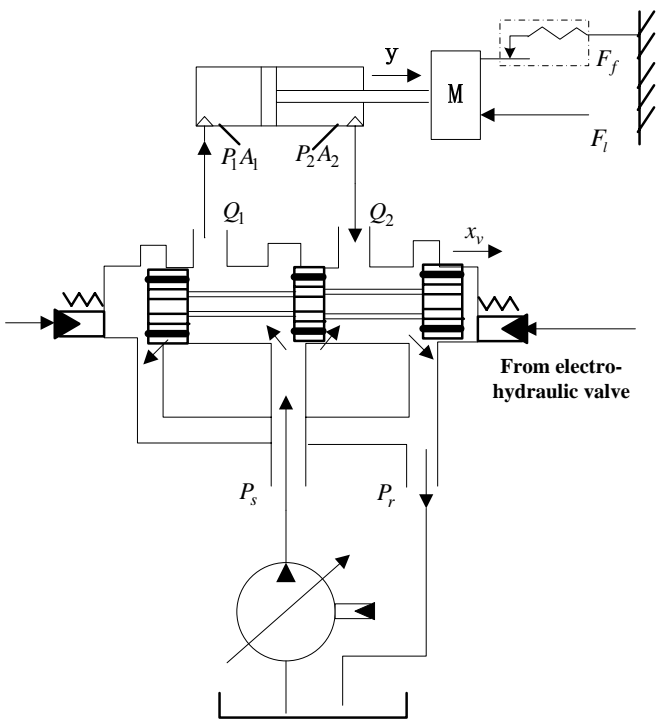

Fig.1 Valve controlled asymmetric cylinder

\section{2 kinematic model}

Kinematic model is helpful for understanding relations between the pose of the bucket and spatial positions of joint-links (Patel et al., 2011). The forward kinematics calculate the pose of the bucket when the joint angles are known, while the backward kinematics figure out all possible sets of joint angles for a appointed bucket pose. Both forward and backward kinematic equations are derived from the fundamental theory for a robotic manipulator, the derivatives of kinematics deal with the mechanics of motion without considering the forces that cause it.

The most extraordinary contribution to kinematics modeling of excavator is due to Koivo (1994), other achievements were either depending on CAD model or similar to Koivos' (Liu, 2005; Zhang, 2006). Koivo defined Cartesian coordinate systems attached to each links and a fixed Cartesian coordinate system with the origin on the ground level in the workspace of the 
excavator (see Fig.2). The coordinate systems are assigned systematically by applying Denavit-Hartenberg procedure. After the coordinate assignment, the forward kinematic relations including equations relating joint angles to bucket pose and equations relating lengths of hydraulic cylinders to joint angles, and backward kinematic relations including equations relating bucket pose to joint angles and equations relating joint angles to lengths of cylinders, and the velocity relations including velocity equations between speeds of bucket and joint shafts and velocity equations between speeds of joins shafts and cylinders were deduced.

The transformation matrix relating two adjacent coordinate frames is as follows:

$$
{ }^{i-1} T_{i}=\left[\begin{array}{cccc}
\cos \theta_{i} & -\cos \alpha_{i} \sin \theta_{i} & \sin \alpha_{i} \sin \theta_{i} & a_{i} \cos \theta_{i} \\
\sin \theta_{i} & \cos \alpha_{i} \cos \theta_{i} & -\sin \alpha_{i} \sin \theta_{i} & a_{i} \sin \theta_{i} \\
0 & \sin \alpha_{i} & \cos \alpha_{i} & d_{i} \\
0 & 0 & 0 & 1
\end{array}\right]
$$

Thus, vector ${ }^{4} \mathrm{P}$ in the fourth coordinate system (Fig. 2 ) and vector ${ }^{0} \mathrm{p}$ in the base coordinate system are related as

$$
{ }^{0} P={ }^{0} T_{4} \square^{4} P={ }^{0} T_{1}^{1} T_{2}^{2} T_{3}^{3} T_{4} \square^{4} P
$$

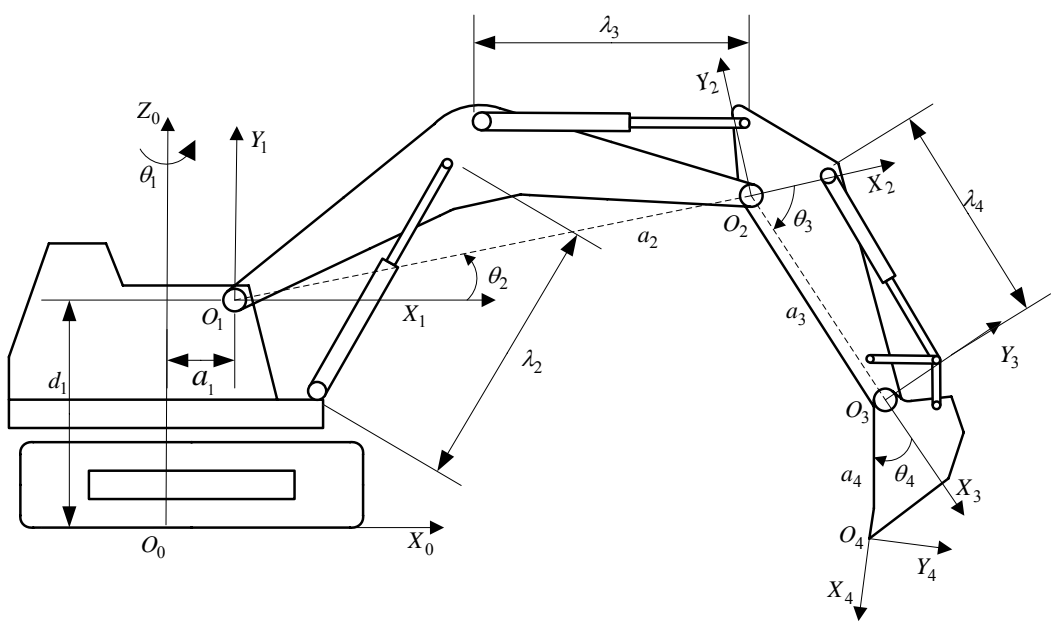

Fig.2 Typical Excavator and Its Coordinate Frames

\section{3 dynamic model}

Kinematic model builds the relationship between bucket trajectory and arm joints, while dynamic model describes the behavior of the robotic excavator system. The dynamic model of the robotic excavator is needed for controller design and system simulation, it is generally expressed in the following vector form (Vaha et al., 1993; Koivo et al., 1996; Zweiri et al., 2006).

$$
M(q) \ddot{q}+V(q, \dot{q})+G(q)=\tau
$$

The dynamic equations of the excavator mechanism can be derived by applying the Euler-Lagrange equations to a Lagrange energy function, or by writing the Newton-Euler equations successively for each link. The application of Euler-Lagrange's equation gives the designer physical insight needed to understand the behavior of the overall system, but it results in high computational cost. On the other hand, the application of Newton-Euler's equations gives a computationally attractive model by its recursive mechanism, but it demolishes the framework of the dynamic model.

Vaha and Skibniewski (1993) built the dynamic model for excavator mechanism by applying Newton-Euler equations of motion to each link (Fig.3 free body) of the machine, and it was refined by Koivo et al., (1996). These iterative equations were used for controller simulations. Shahram et al. (1997) developed the whole dynamics of a teleoperated mini excavator for parameter identification by Euler-Lagrange's equations. The CAD models (Fig.4) for dynamic simulation of the robotic excavator were also developed by many other researchers (Park, 2002; Liu, 2005). 


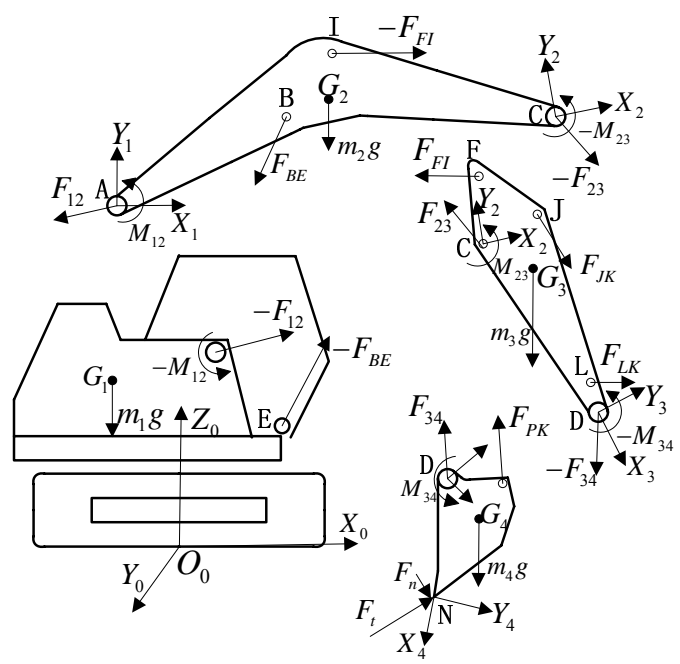

Fig.3 Free body diagrams of excavator mechanism

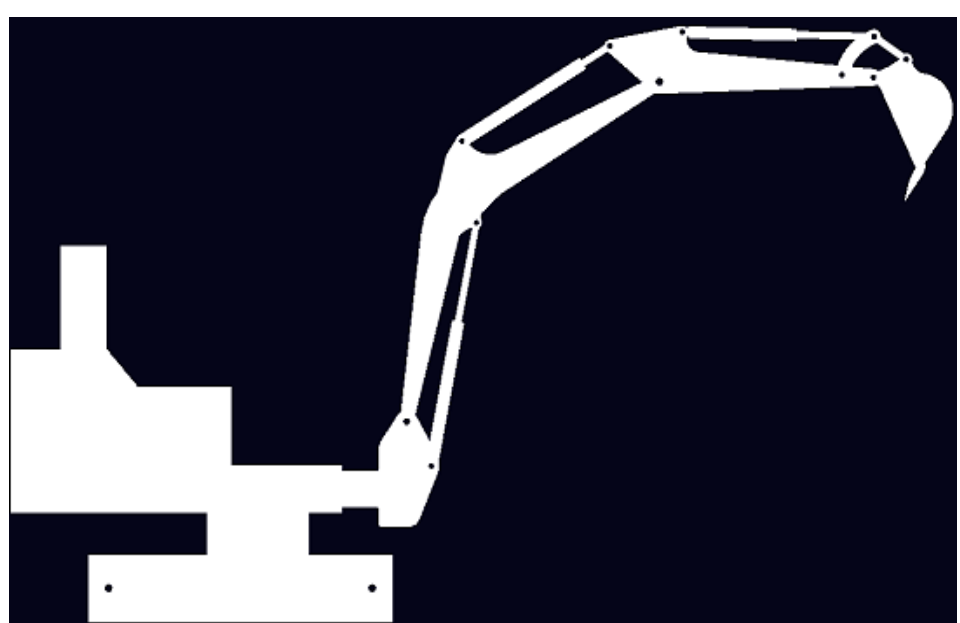

Fig.4 ADAMS model of the robotic excavator

\section{4 soil-tool model}

Knowing the rigid-body dynamics of robotic excavator is not good enough for controller design, it is necessary to develop the soil-tool interaction model. Usually, the robotic excavator is required to carry out tasks involving contacting with its environment, such as leveling and digging. Excavation is defined as a sense of loading a bucket with soil or fragmented rock, the action comprises a combination of penetration, cutting and breaking of material, followed by scooping to remove material for loading (Lipsett et al., 2011).The knowledge of force encountered by bucket in earthmoving operations is important for controller design and safety monitoring.

Earlier researchers directly modeled the bucket-soil interaction force as Fig.5 (Koivo et al., 1996; Ha et al., 2000), and added it to manipulator's dynamic models, but, this method cannot predict resistive force experienced at the bucket while tracking the settled trajectory. It is shown that finite-element method allows high modeling accuracy for soil dynamics. However, it is not suitable for real time implementation on the robotic excavator due to its computational expense (Hong, 2001). Coetzee et al. (2007) used a so called meshless finite element method (MPM) to overcome the difficulty in modeling the entire bucket filling process encountered by standard finite element method due to large displacements and distortions of the mesh. Both their materialpoint method for continuum modeling and discrete element method for discrete modeling can accurately predicted the bucket force, but neither method suits online application. Parameter models of soil-tool interaction based on Mohr-Coulomb or CLUB soil model (Figure.7) built for autonomous excavation were reported by Luengo et al., (1998), Tan et al., (2005), Althoefer et al., (2009), these models were identified for impedance control. A second-order rheological type of model (Fig.6) for compliance control was developed by Richardson-Little et al. (2008). This type of mass-spring-damper system has two key advantages over quasistatic model: 1) the dynamic interaction can be made passive and 2) it can be easily implemented in an excavation simulation.

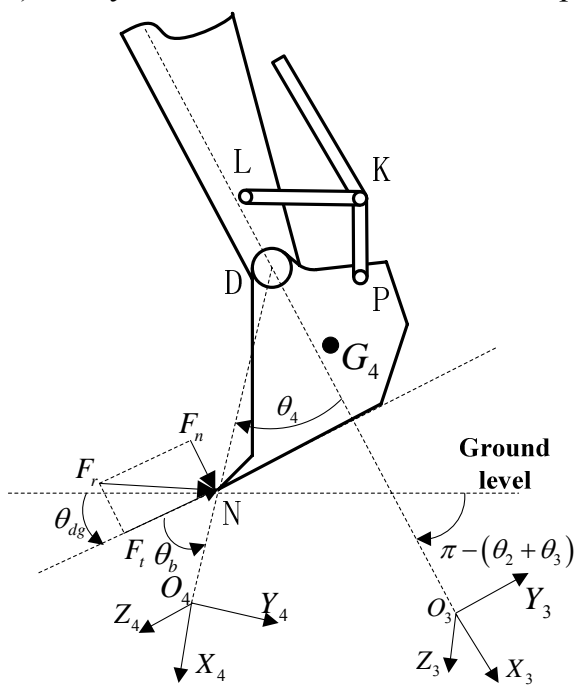

Fig.5 Interaction force

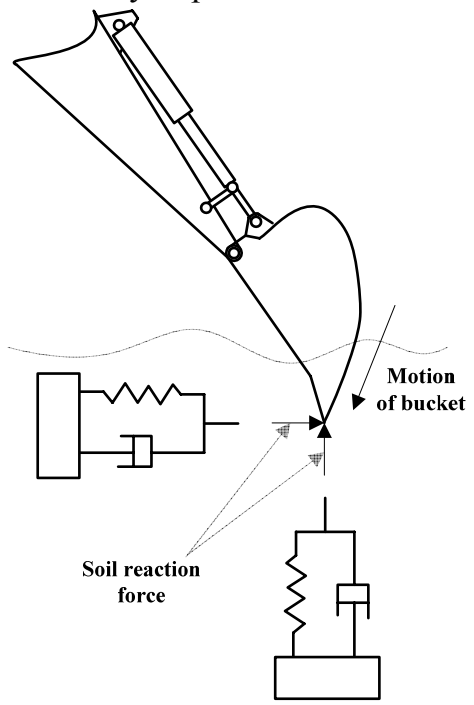

Fig.6 Rheological model 


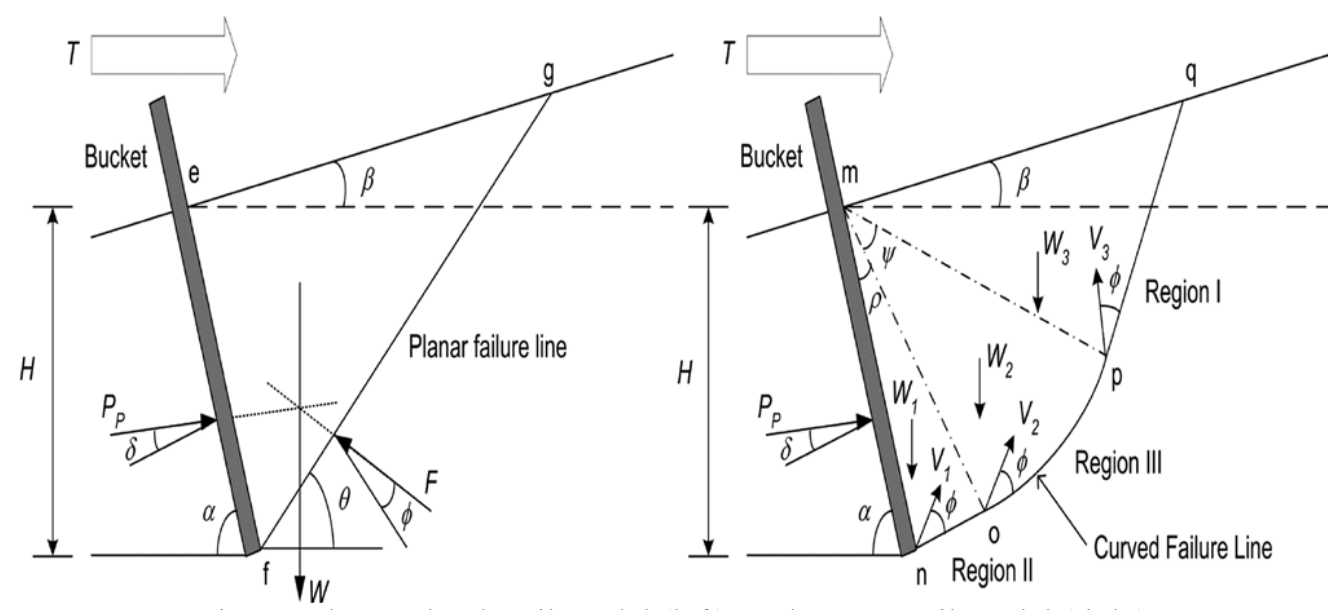

Fig.7 Mohr-Coulomb soil model (left), and CLUB soil model (right)

\section{5 discussion}

For system analysis and controller design purposes, one always gave out the actuator dynamics, soil-tool dynamics, kinematics, and dynamics of the manipulator respectively. However, the bond graph method can describe the interactive dynamics of all types of engineering system by a few symbols in a uniform procedure (Margolis et al., 2005). Muvengei et al. (2009) modeled the mechanical dynamics of an excavator by bond graphs, they indicated that bond graph method was more computationally efficient than Newton-Euler method. Margolis et al. (2003; 2005) modeled the mechanical dynamics, hydraulic dynamics, and the tire ground dynamics for an excavator respectively and combined these individual subsystems into an overall computational model by bond graphs. Papadopoulos et al. (2003) implemented a linear-graph method to integrated manipulator dynamics and actuation dynamics into a complete machine model for a harvester machine. All of these demonstrate that bond graph method may be a great method for modeling the coupling dynamics of robotic excavator.

\section{System identification}

Since the dynamic models of the robotic excavator are established, the challenge is to find robust and computational efficient methods to estimate unknown parameters for the developed models through measured date. A good parameter identification scheme provides benefits: 1) model based position control, 2) on-line system monitoring, 3) simulation of the machine behavior, and 4) compensation of the nonlinear dynamics, manipulator link weights and soil-tool interaction force in control. This section focuses on the system identification problems.

Hydraulic actuators have significant nonlinearities and uncertainties, which complicate the controller design. To facilitate analyzing and control design, some researchers used linear methods to identify the hydraulic system (He et al., 2008; Tafazoli, 1997), but the results were not good enough. Wang et al. (2010) proposed a neural network based method to identify the unknown parameters of hydraulic actuators, and the results were demonstrated to be more accuracy.

Robotic excavator has a manipulator-like structure with four degrees of freedom, identification of the link parameters (mass, inertia) and friction coefficient is a key requirement in field implementations. Tafazoli transformed the rigid-body dynamic equations into a form which was linear in the inertia and friction-related parameters, he used the LS method to figure out the lumped unknown parameters and shown that the identified model predicted the joint toques with an acceptable accuracy (Tafazoli, 1997). On the contrary, Zweiri et al. proposed three identification methods, Newton-Raphson, generalized Newton, and least squares, to identify all the unknown individual parameters for a unmanned excavator( Zweiri et al., 2004; Zweiri, 2008), their testing results shown that both the Newton-Raphson and general Newton method had better prediction accuracy, and the NewtonRaphson method had the best computational speed.

Prediction of the soil-tool interaction force using a parametric formulation depends on accurate estimations of the soil parameters. Vahed et al. (2008), and Dai et al. (2011), employed an energy-based approach for online soil type identification respectively. the algorithm worked in real time, and was sufficiently fast for practical implementation in typical low/high level control employed for autonomous excavation. Tan et al. (2005) proposed a scheme based on Newton-Raphson method to estimate the parameters of soil density and soil-soil friction angle for the Mohr-Coulomb and CLUB soil model respectively, while Althoefer et al. (2009) used the modified Newton-Raphson method to estimate the four unknown parameters: soil-soil friction angle, soil density, soil-tool friction angle, and cohesion. 


\section{Servo control}

The behavior of the robotic excavator is dominated by the nonlinear dynamics of the hydraulic actuators and by the coupled dynamics of the series manipulators and by the uncertain bucket-soil interaction forces. This makes the control of robotic excavator different from conventional manipulators; control designers have to considerate all the aspects mentioned above. This section focuses on the low level servo control problems.

\section{1 robust trajectory tracking}

There were lots of methods dealing with position servo control of robotic excavator, they tried to overcome the nonlinear dynamics, variation parameters, and unpredicted external disturbance to track the desired trajectory accurately. Conventional PD and PID controller were adapted by Sepehri et al. (1994), Koivo et al. (1996), and Gao et al. (2009), they got satisfied results only in simple backgrounds. In order to overcome hydraulic nonlinear dynamics, feedback linearization control was proposed by Nguyen et al. (1999). One of the main disadvantages of feedback linearization control is that it requires an exact system model which is hard to provide on a robotic excavator. Subsequently, Ha et al. (2001), introduced a variable structure sliding mode controller with a fuzzy control component to reduce chattering to provide an effective and robust means of controlling the nonlinear system in the presence of severe uncertainties. A similar adaptive fuzzy sliding mode controller was adapted by Zhang et al. (2010) to track a 4 DOF automatic excavator. Yao et al. (1998) proposed a high performance adaptive robust controller to track the swing velocity of an excavator. Chiang et al. (2004) adopted a model reference adaptive controller with on-line self-turning algorithm to implement complex path tracking experiments for a large robotic excavator. As the size of an excavator become larger, the nonlinearities and uncertainties become more severe, Chang, and Lee adopted a time-delay control with compensators coming from the nonlinearity analysis to track straight-lines on a 13-ton excavator (Chang et al., 2000). Later, they proposed a time-delay control with switching action (TDCSA) using an integral sliding surface to a 21-ton excavator (Lee et al., 2002), both of the experiments shown good tracking performance.

Other methods like PIP control (Gu et al., 2004; 2009), load-independent control (Budny et al., 2003), neural network and its refined control (Song et al., 1995; Hanh et al., 2009) were also turned out to have robust tracking properties.

\section{2 compliance control}

Robust position control was proposed to cope with hydraulic nonlinearities, coupling manipulator dynamics, and system uncertainties. However, robotic excavators are always subject to wide variation of soil-tool interaction forces in digging processes. Compliance controller is considered to be more suitable than position control for allowing the robotic excavator to be able to operate in all three states of manipulator motions: free space, contact, and exertion of a force against an environment.

A cognitive force control strategy was developed by Vaha et al. (1993), the controller could regulate the depth and trajectory speed according to the ram-force. A hybrid force/position control was proposed by Nguyen et al., (2000) to track a desired position and a reference force. According to the disadvantage of force/position control that the control mode is required to switch between position and force control which may cause excessive force transients at the instant of contact, Ha et al., (2000) developed a fuzzy sliding mode controller which implemented impedance control for the backhoe excavator. It is known that impedance control provide a unified approach to both free and constrained motion, it is believed to be more suitable for robotic excavation. Tafazoli et al. (2002) adopted a position based impedance control to an instrumented mini-excavator, various contact experiment results shown that in impedance mode, the bucket trajectory did comply to the environment constraint, transient forces were lower, and steady-state contact forces tend to zero, while in position control, interaction forces are significantly higher. Richardson-Little et al. (2008) proposed a position accommodation/compliance control which was similar to position based impedance control for robotic excavations, the comparison results shown that it allowed for better control of the complete excavation cycle.

\section{3 discussion}

There are several limitations to current control methods. Robotic excavator is a mobile vehicle with hydraulic manipulator mounted on it, when moving the manipulators, the body of the robotic excavator may be compelled to slip or vibrate (Abo-Shanab et al., 2005). At this time, the position tracking algorithms fails to deliver the right motions.

We have just discussed the low level servo control problems here, besides, various intelligent control methods for task planning or navigation had been studied to demonstrate fully autonomous execution of excavation tasks in unknown environment (Singh, 1995; Rowe, 1999; Shi et al., 1996; Wang, 2004.). The hot topics of vision-based control (Saeedi et al., 2005), haptic control (Kontz, 2007), and remote teleoperation (Krishnaswamy, 2004; Kim et al., 2009) are also not discussed here.

\section{Conclusion}

Robotic excavation provides benefits like: improving machine utilization and throughput, minimizing the risk of operator while working in hazardous environments, and lowering operator work load. However, full or partial automation of the excavator has been slowly accepted by industry. As computing and sensing technologies have been steadily improved, automation of the excavation process through the adoption of robotics technologies appears to be possible. This paper has reported the works 
conducted to develop the robotic excavator form system modeling to servo control. But, for commercial usage, there are still lots of works to be done.

For implementing robotic excavation, the dynamic models of the machine must be developed and the unknown parameters of system should be identified. Subsequently, robust position controller or compliance controller must be designed carefully based on the identified models. The current methods of modeling the robotic excavator have been discussed above, and a proposal based on bond graph modeling is presented for future works. The current servo control methods based on the identified dynamic models are also reviewed, and their limitations are pointed out for improvement. However, the high-level control issues including environment sensing, navigation and tasks planning are not discussed here.

\section{References}

Abo-Shanab R.F., and Sepehri N., 2005. Tip-over stability of manipulator-like mobile hydraulic machines, Journal of Dynamic Systems, Measurement, and Control, Vol.127, pp.295-301.

Althoefer K., Tan P.C., Zweiri Y.H., and Seneviratne L.D., 2009. Hybrid soil parameter measurement and estimation scheme for excavation automation, IEEE Transactions on Instrumentation and Measurement, Vol.58, No.10, pp.3633-3641.

Bradley D.A., and Seward D.W., 1998. The development, control and operation of an autonomous robotic excavator, Journal of Intelligent and Robotic System, Vol.21, pp.73-97.

Budny E., Chlosta M., and Gutkowski W., 2003. Load-independent control of a hydraulic excavator, Automation in Construction, Vol.12, pp.245-254.

Chang P.H., and Lee S.J., 2002. A straight-line motion tracking control of hydraulic excavator system, Mechatronics, Vol.12, pp.19-138.

Chiang M.H., and Huang C.C., 2004. Experimental implementation of complex path tracking control for large robotic hydraulic excavators, International Journal of Advanced Manufacturing and Technology, Vol.23, pp.126-132.

Coetzee C.J., Basson A.H., and Vermeer P.A., 2007. Discrete and continuum modeling of excavator bucket filling, Journal of Terramechanics, Vol.44, pp.177-186.

Dai J.S., Lam H.K., and Vahed S.M., 2011. Soil type identification for autonomous excavation based on dissipation energy, Proceedings of the Institution of Mechanical Engineers, Part I: Journal of Systems and Control Engineering, Vol.225, pp.35-50.

Gu J., Taylor J., and Seward D., 2004. Proportional-integral-plus control of an intelligent excavator, Computer-Aided Civil and Infrastructure Engineering, Vol.19, pp.16-27.

Gu J. and Seward D.W., 2009. Digital servo control of a robotic excavator, Chinese Journal of Mechanical Engineering, Vol.22, No.2, pp.190-197.

Gao Y.J., Jin Y.C., and Zhang Q., 2009. Motion planning based coordinated control for hydraulic excavators, Chinese Journal of Mechanical Engineering, Vol.22, No.1, pp. 97-101.

Ha Q.P., 2004. A control architecture for robotic excavation in construction, Computer-Aided Civil and Infrastructure Engineering, Vol.19, pp.28-41.

Ha Q.P., Nguyen Q.H., Rye D.C., and Durrant-Whyte H.F., 2000. Impedance control of a hydraulically actuated robotic excavator, Automation in Construction, Vol.9, No.5, pp.421-435.

Ha Q.P., Nguyen Q.H., Rye D.C. and Durrant-Whyte H.F., 2001. Fuzzy sliding-mode controllers with applications, IEEE Transactions on Industrial Electronics, Vol.48, No.1, pp.38-47.

Ha Q., Santos M., Nguyen Q., Rye D., and Hugh D.W., 2002. Robotic excavation in construction automation, IEEE Robotic \& Automation Magazine, Vol.2, No.1, pp.20-28.

He Q.H., Hao P., and Zhang D.Q., 2008. Modeling and parameter estimation for hydraulic system of excavator's arm, Journal of Central South University of Technology (English Edition), Vol.15, pp.382-386.

Kim D., Kim J., Lee K., Park C., Song J., and Kang D., 2009. Excavator tele-operation system using a human arm, Automation in Construction, Vol.18, pp.173-182.

Hong W., 2001. Modeling, estimation, and control of robot-soil interactions, PhD thesis of Massachusetts Institute of Technology.

Koivo A.J., 1994. Kinematics of excavators (Backhoes) for transferring surface material, Journal of Aerospace Engineering, Vol.7, No.11, pp.17-32.

Koivo A.J., Thoma M., Kocaoglan E., and Andrade-Cetto J., 1996. Modeling and control of excavator dynamics during digging operation, Journal of Aerospace Engineering, Vol.9, No.1, pp.10-18.

Kontz M.E., 2007. Haptic control of hydraulic machinery using proportional valves, PhD Thesis of G.W. Woodruff School of Mechanical Engineering, Georgia Institute of Technology.

Krishnaswamy K., 2004. Passive teleopration of hydraulic systems, PhD Thesis of University of Minnesota, Minneapolis, Minnesota.

Le D.H., Kyoung K.A., Nguyen B.K., and Jo W.K., 2009. Trajectory control of electro-hydraulic excavator using fuzzy self tuning algorithm with neural network, Journal of Mechanical Science and Technology, Vol.23, pp.149-160.

Lee S.U., and Chang P.H., 2002. Control of a heavy-duty robotic excavator using time delay control with integral sliding surface, Control Engineering Practice, Vol.10, pp.697-711. 
Lipsett M.G., and Moghaddam R.Y., 2011. Modeling excavator-soil interaction, Springer Series in Geomechanics and Geoengineering, Vol.0, pp.347-366.

Liu J., 2005. Investigation on modeling of a virtual robotic excavator prototype and the application technology, PhD Thesis of Zhejiang University, Hangzhou, China. (in Chinese).

Luengo O., Singh S., and Cannon H., 1998. Modeling and identification of soli-tool interaction in automated excavation, Proceedings of the IEEE/RSJ Intl. Conf. on Intelligent Robots and Systems, Victoria, B.C., Canada.

Margolis D., and Shim T., 2003. Instability due to interacting hydraulic and mechanical dynamics in backhoes, Journal of Dynamic Systems, Measurement, and Control, Vol.125, pp.497-504.

Margolis D., and Shim T., 2005. Bond graph modeling for non-linear hydro-mechanical systems, Proc. IMechE, Vol.219, Part K: J. Multi-body Dynamics, pp.371-382.

Muvengei M., and Kihiu J., 2009. Bond graph modeling of mechanical dynamics of an excavator for hydraulic system analysis and design, International Journal of Mechanical, Industrial and Aerospace Engineering, Vol.3, No.4, pp.248-256.

Nguyen Q.H., 2000. Robust low level control of robotic excavation, PhD Thesis, The University of Sydney, Australia.

Nguyen Q.H., Ha Q.P., Rye D.C., and Durrant-Whyte H.F., 1999. Feedback linearization control for electro-hydraulic systems of a robotic excavator, Proceedings of the Australian Conference on Robotics and Automation, Brisbane, Australia, pp.190-195.

Park B., 2002. Development of a virtual reality excavator simulator: a mathematical model of excavator digging and calculation methodology, PhD Thesis of Virginia Polytechnic Institute and State University, Blacksburg, Virginia.

Papadopoulos E., Mu B., and Frenette R., 2003. On modeling, identification, and control of a heavy-duty electrhydraulic Harvester Manipulator, IEEE Transactions on Mechatronics, Vol.8, No.2, 178-187.

Płonecki L., Tra mpczyn'ski W., and Cendrowicz J., 1998. A concept of digital control system to assist the operator of hydraulic excavators, Automation in Construction, Vol.7, pp. 401-411.

Patel B.P., and Prajapati D.J.M., 2011. A review on kinematics of hydraulic excavator's backhoe attachment, International Journal of Engineering Science and Technology, Vol.3, No.3, pp.1990-1997.

Rowe P.S., 1999. Adaptive motion planning for autonomous mass excavation, PhD thesis of Carnegie Mellon University, Pittsburgh, Pennsylvania.

Richardson-Little W., and Damaren C., 2008. Position accommodation and compliance control for robotic excavation, Journal of Aerospace Engineering, Vol.21, No.1, pp. 27-34.

Saeedi P., Lawrence P.D., Lowe D.G., Jacobsen P., Kusalovic D., Ardron K., and Sorensen P.H., 2005. An autonomous excavator with vision-based trak-slippage control, IEEE Transactions on Control Systems Technology, Vol.13, No.1, pp.67-84.

Sepehri N., Lawrence P.D., Sassani F. and Frenette R., 1994. Resolved-Mode Teleoperated Control of Heavy-Duty Hydraulic Machines, Journal of Dynamic Systems, Measurement, and Control, Vol.116, No.2, pp.232-240.

Singh S., 1995. Learning to predict resistive forces during robotic excavation, Proceedings of the Intl. Conf. on Robotics and Automation, Nagoya, Japan.

Singh S, 1995. Synthesis of tactical plans for robotic excavation, $\mathrm{PhD}$ thesis of Carnegie Mellon University, Pittsburgh, Pennsylvania.

Singh S., 1997. The state of the art in automation of earthmoving, ASCE Journal of Aerospace Engineering, Vol.10, No.4, pp.1-30.

Shi X.B., Lever P.J.A., and Wang F.Y., 1996. Fuzzy Behavior Integration and Action Fusion for Robotic Excavation, IEEE Transactions on Industrial Electronics, Vol.43, No.3, pp.395-401.

Song B., and Koivo A.J., 1995. Neural adaptive control of excavators, Proceeding of the IEEE/RSJ International Conference on Intelligent Robots and Systems.

Stentz A., Bares J., Singh S., and Rowe P., 1998. A robotic excavator for autonomous truck loading, Proceedings of the 1998 IEEE/RSJ Intl. Conference on Intelligent Robots and Systems, Victoria, B.C., Canada.

Tafazoli S., 1997. Identification of friction effects and structural dynamics for improved control of hydraulic manipulators, $\mathrm{PhD}$ Thesis of University of British Columbia, Vancouver, Canada.

Tafazoli S., Lawrence P.D. and Salcudean S.E., 1999. Identification of inertial and friction parameters for excavator arms, IEEE Transactions on Robotics and Automation, Vol.15, No.5, pp.966-971.

Tafazoli S, Salcudean S.E, Hashtrudi-Zaad K., and Lawrence P.D., 2002. Impedance control of a teleoperated Excavator, IEEE Transactions on Control Systems Technology, Vol.10, No.3, pp.355-366.

Tan C.P., Zweiri Y.H., Althoefer K., and Seneviratne L.D., 2005. Online soil parameter estimation scheme based on NewtonRaphson method for autonomous excavation, IEEE/ASME Transactions on Mechanics, Vol.10, No.2, pp.221-229.

Vaha P.K., and Skibniewski M.J., 1993. Dynamic model of excavator, Journal of Aerospace Engineering, Vol.6, No.2, pp.148158.

Vaha P.K., and Skibniewski M.J., 1993. Cognitive force control of excavators, Journal of Aerospace Engineering, Vol.6, No.2, pp.159-166.

Vahed, S.M., Song X.J., Dai J.S., Lam H.K., Seneviratne L.D., and Althoefer K., 2008. Soil estimation based on dissipation energy during autonomous excavation, The International Federation of Automatic control, Seoul, Korea.

Wang F.B., Liu J., Chen Z.K. and Zeng X.L., 2010. RBF parameter identification of valve-controlled cylinder system for excavator robot, Journal of Northeastern University (Natural Science), Vol.31, No.10, pp.1476-1478. (in Chinese). 
Wang F.Y., 2004. Agent-based control for fuzzy behavior programming in robotic excavation, IEEE Transactions on Fuzzy Systems, Vol.12, No.4, pp.540-548.

Yan J., Li B., Tu Q.Z., Guo G., and Zeng Y.H., 2011. Automatization of excavator and study of its autocontrol, Third International Conference on Measuring Technology and Mechatronics Automation, Shanghai, China, pp.604-609.

Yao B., Bu F., Reedy J., and ChiuT.C., 2000. Adaptive robust motion control of single-rod hydraulic actuators: theory and experiments, IEEE/ASME Transactions on Mechatronics, Vol.5, No.1, pp.79-91.

Yao B., Zhang J., Koehler D., and Litherland J., 1998. High performance swing velocity tracking control of hydraulic excavators, Proceedings of the American Control Conference, Philadelphia, Pennsylvania.

Yu H., Liu Y., and Hasan M.S., 2010. Review of modeling and remote control for excavators, Int. J. Advanced Mechatronic Systems, Vol.2, Nos.1/2, pp.68-80.

Zhang D.Q., 2006. Research on motion control of manipulator of hydraulic excavator, PhD Thesis of Center South University, ChangSha, China. (in Chinese).

Zhang J.P., Liu K., Lin J.F., Ma X., and Yu W.D., 2010, 4 DOF adaptive fuzzy sliding mode control of excavator, Journal of Mechanical Engineering, Vol.46, No.21, pp.87-92.( in Chinese).

Zweiri Y.H., 2008.Identification schemes for unmanned excavator arm parameters, International Journal of Automation and Computing, Vol.5, No.2, pp.185-192.

Zweiri Y.H., Seneviratne L.D., and Althoefer K., 2004. Parameter estimation for excavator arm using Generalized Newton Method, IEEE Transactions on Robotics, Vol.20, No.4, pp. 762-767.

Zweiri Y.H., Seneviratne L.D., and Althoefer K., 2006. Modelling of closed-chain manipulators on an excavator vehicle, Mathematical and Computer Modelling of Dynamical Systems, Vol.12, No.4, pp.329-345.

\section{Biographical notes}

Yan Jun is currently a professor in Engineering Institute of Corps of Engineer, PLA Univ. of Science and Technology, China. His research interests include Military Equipment management and so on.

Li Bo was born in china in 1985. He is currently a graduate student of doctor in Engineering Institute of Corps of Engineer, PLA Univ. of Science and Technology, China. His research interests include filed robotics, modeling and control of hydraulic equipments.

Zeng Yonghua is currently a lecturer in Engineering Institute of Corps of Engineer, PLA Univ. of Science and Technology, China. His research interests include Military Equipment management and maintenance.

Qian Haibo is currently a graduate student of doctor in Engineering Institute of Corps of Engineer, PLA Univ. of Science and Technology, China. His research interests include equipment management and maintenance.

Received September 2011

Accepted September 2011

Final acceptance in revised form May 2013 